\title{
Classification scheme for random longitudinal road unevenness considering road waviness and vehicle response
}

\author{
Oldřich Kropáča and Peter Múčkab,* \\ ${ }^{a}$ Kaňkovského 1241/2, CZ-182 00, Prague 8, Czech Republic \\ ${ }^{\mathrm{b}}$ Institute of Materials and Machine Mechanics, Slovak Academy of Sciences, Račianska 75, SK-831 02 Bratislava \\ 3, Slovak Republic
}

Received 24 August 2007

Revised 7 March 2008

\begin{abstract}
A novel approach to the road unevenness classification based on the power spectral density with consideration of vehicle vibration response and broad interval of road waviness (road elevation PSD slope) is presented. This approach enables transformation of two basic parameters of road profile elevation PSD (unevenness index, $C$, and waviness, $w$ ) into a singlenumber indicator $C_{\mathrm{w}}$ when using a correction factor $K_{\mathrm{w}}$ accounting for $w$. For the road classification proposal two planar vehicle models (passenger car and truck), ten responses (reflecting ride comfort, dynamic load of road and cargo, ride safety) and three different vehicle velocities have been considered. The minimum of ten estimated vibration response ranges sum for a broad waviness interval typical for real road sections ( $w=1.5$ to 3.5$)$ has been used for the correction factor estimation. The introduced unevenness indicator, $C_{\mathrm{w}}$, reflects the vehicle vibration response and seems to be a suitable alternative to the other currently used single-number indicators or as an extension of the road classification according to the ISO 8608: 1995, which is based on constant waviness value, $w=2$.
\end{abstract}

Keywords: Road profile, waviness, unevenness index, power spectral density (PSD), International Roughness Index (IRI), half-car model, vibration response, road-vehicle interaction

\section{Introduction}

Suitably selected indicators of longitudinal road unevenness are necessary for all stages of the ground traffic policy beginning with the planning of the road net and design of its individual partial sections, followed with its construction including running quality control of the making, and finally managing its performance and maintenance. Two distinctly different approaches to this task may be distinguished.

First, only the geometry of the elevation change in dependence on the track distance, the so-called longitudinal profile, is considered. At the beginning of the past century, the maximum clearance between a lath, laid on the road and its surface, related to the distance between the contact points, provided a heuristic approach to this matter. This procedure, repeatedly applied along the track and taking the mean value of all readings, resulted in an empirical indicator which is used up-to-date, usually in some mechanized version $[8,21,22]$. The statistical conception of the longitudinal profile, considered to be realization of a random function and introduced in the 1960th revealed that for the description of the relevant characteristic of road unevenness, the power spectral density (PSD), assumed even in its simplest form, two independent parameters are necessary. Any generalization of the PSD shape [1,20] requires

\footnotetext{
${ }^{*}$ Corresponding author. Tel.: +421 25930 9402; Fax: +421 25477 2099; E-mail: ummsmuc@ @avba.sk.
} 
even greater number of additional independent parameters, which in our case play the role of further unevenness indicators.

The second approach to the road unevenness valuation is based on the reasoning that what is important for the current user of the road net is the knowledge of the effects which the unevenness causes on the traversing vehicle and not the knowledge of indicators of the unevenness alone. These effects reflect the travel safety and comfort of seated people, further on the dynamic loading of pavement, vehicle and freight. Therefore, several one-purpose measuring devices were developed and used in practice [7,8,21,22]. They produced single indicators [8,29], which were tightly bound to the physical principle, and particular realization structure of the device, but without any direct link to other devices based on different ideas and structural realizations. One of the most popular devices of this kind was the so-called Bump Integrator, in principle a two-mass vehicle model, in which the absolute suspension movement summarize. The algorithmic formalization of this device with parameters tuned up to produce its frequency response function as nearly flat as possible resulted in the common International Roughness Index (IRI) [2,23].

The authors of this paper are interested in the vehicle dynamics for which the full description of the unevenness PSD is indispensable. Using it, all problems considering different vehicle structures, physical quantities and measuring points of interest as well as travel speed can arbitrarily be set up. Therefore, the authors plead for the more precise description of road unevenness also among the community of transport engineers [14]. On the other hand, they also understand the call for as simple as possible description of the longitudinal road unevenness required from the road management authorities, which are faced the situation that a number of further indicators must be accounted for to assess the all-round road performance ability. In paper [16], some methodological tools for this task were worked-out and a short excerption from them is given in the sequel in Section 2. The new results that tackled the problem of appropriate implementation of vibration response for different vehicles, different vibration measures on vehicle and different road design speeds into the road classification scheme are presented in Sections 3 to 5.

\section{Background relationships}

The measured longitudinal road profile $h(l)$, where $h[\mathrm{~m}]$ is the road elevation dependent on the distance $l[\mathrm{~m}]$ along the track, is considered to be a realization of a random function $H(l)$. Provided that this function is centred, homogeneous, and Gaussian, it is fully described by its power spectral density (PSD) $G_{\mathrm{H}}(\Omega)\left[\mathrm{m}^{3} / \mathrm{rad}\right]$, where $\Omega$ $[\mathrm{rad} / \mathrm{m}]$ is the angular spatial frequency $[3,17,20]$. Instead of this quantity, its reciprocal value, the wavelength $L[\mathrm{~m}]$ $=2 \pi / \Omega$ is often used.

The simplest analytical expression of the PSD has the form $[1,10]$

$$
G_{\mathrm{H}}(\Omega)=C \Omega^{-w},
$$

where $C\left[\operatorname{rad}^{w-1} \mathrm{~m}^{3-w}\right]=G_{\mathrm{H}}(1)$ is the unevenness index, and $w$ [1] is the waviness.

This function depicts in the $\log -\log$ plot as a straight line with $C$ as its vertical position and $w$ as its slope (Fig. 1).

The estimation of parameters $C$ and $w$ from the measured road profile $h(l)$ is given in the standards ISO 8608: 1995 [10] and EN 13036-5: 2006 [9]. A short characterization of these standards is given in Appendix 1. In Annex C.4, Table C.2 of the ISO 8608 Standard, (see also Table A1), a classification of road unevenness according to $C$ values is proposed for the waviness $w=2$. Nevertheless, measurements and processing [15] of unevenness data conducted on large road networks in the United States [6], Germany [4] and Sweden [1] revealed that the waviness of in-service roads moves in a relatively broad interval from 1.5 to 3.5 (see Fig. 2). Note, that the question of road waviness influence on the vehicle vibration response is tackled only marginally in the references $[17,19$, 24,26-28]. Furthermore, the previously mentioned classification is absolute and does not reflect the fundamental effect of vehicle design and current traffic speed on the assessment of the road performance ability. Therefore, the expression of the response of travelling vehicle to the road unevenness is necessary.

When a vehicle travels at a speed $v[\mathrm{~m} / \mathrm{s}]$ on an uneven road characterized by its elevation $\operatorname{PSD} G_{\mathrm{H}}(\Omega$, this function defined in the spatial domain changes into an equivalent function in the time domain $G_{\mathrm{H}}(\omega)$ which is given by the relation

$$
G_{\mathrm{H}}(\omega)=G_{\mathrm{H}}(\Omega) / v,
$$




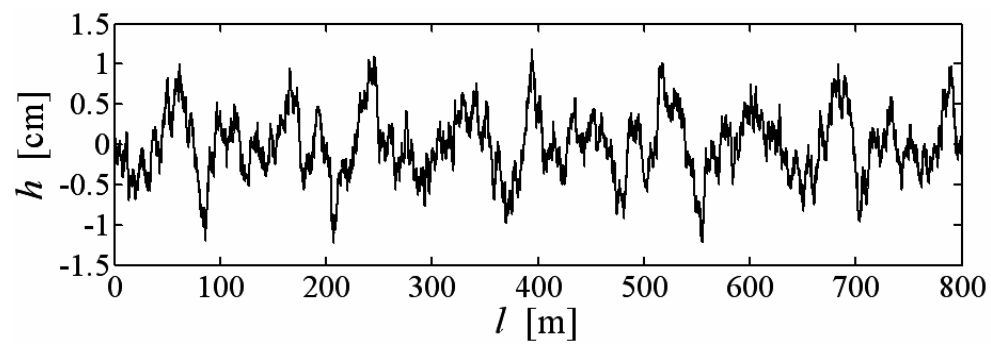

(a)

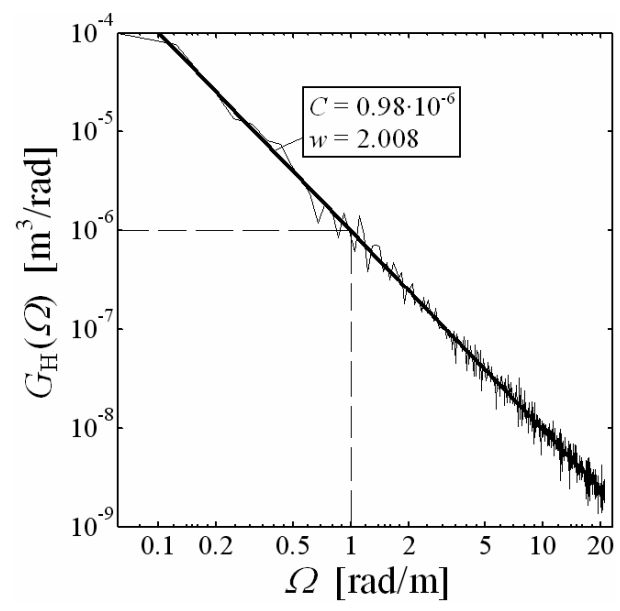

(b)

Fig. 1. An example of simulated longitudinal road profile (a), and the corresponding PSD (b) for $C_{\text {nom }}=1 \times 10^{-6} \mathrm{rad} \mathrm{m}, w_{\text {nom }}=2$.

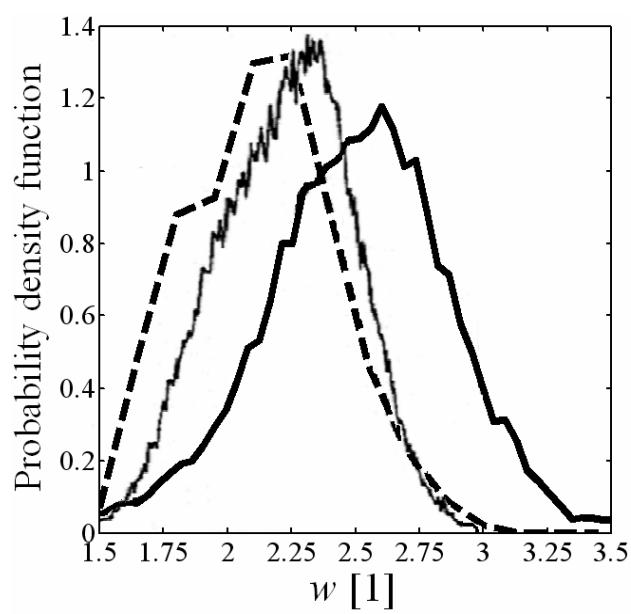

Fig. 2. Probability density function of waviness estimated for road sections: USA Sweden (—) - entire Swedish network.

where $\omega[\mathrm{rad} / \mathrm{s}]$ is the angular frequency $(\omega=\Omega v)$. The vehicle may be modelled as a linear dynamic system with constant parameters with the frequency response function $H_{\mathrm{HY}}(\mathrm{j} \omega)$ between the displacements on the input (contact of the vehicle tyre with a road) and output (the particularly selected reference point of the vehicle). For the PSD of the displacement response $Y(t)$ in this reference point, the relation [3,17] 


$$
G_{\mathrm{Y}}(\omega)=\left|H_{\mathrm{HY}}(\mathrm{j} \omega)\right|^{2} G_{\mathrm{H}}(\omega)
$$

holds. Inserting for $G_{\mathrm{H}}(\omega)$ from the relations (1) and (2), we obtain

$$
G_{\mathrm{Y}}(\omega)=\left|H_{\mathrm{HY}}(\mathrm{j} \omega)\right|^{2} C \omega^{-w} v^{w-1} .
$$

For practical reasons, it is often more advantageous to consider acceleration response $A(t)=d^{2} Y(t) / d t^{2}$ (the frequency response function denoted as $H_{\mathrm{HA}}(\mathrm{j} \omega)$ ) instead of displacement $Y(t)$. Then, the PSD of the acceleration response $A(t)$ takes the form

$$
G_{\mathrm{A}}(\omega)=\left|H_{\mathrm{HY}}(j \omega)\right|^{2} C \omega^{4-w} v^{w-1}=\left|H_{\mathrm{HA}}(j \omega)\right|^{2} C \omega^{-w} v^{w-1} .
$$

Often, when a simple description of the system response in terms of output variance $D_{\mathrm{A}}$ is sufficient, this quantity is obtained by integrating $G_{\mathrm{A}}(\omega)$ over the range of effectively acting frequencies $\omega$, thus resulting in

$$
D_{\mathrm{A}}=C I_{\mathrm{w}} v^{w-1},
$$

where $I_{\mathrm{w}}$ is the integrated frequency response in which the waviness also manifests itself and for acceleration response is evaluated as

$$
I_{\mathrm{w}}=\int_{\omega}\left|H_{\mathrm{HA}}(\mathrm{j} \omega)\right|^{2} \omega^{-w} d \omega .
$$

It was found out that for a broad variety of vehicle configurations and vibration responses, the structure of functions $I_{\mathrm{w}}$ is similar and may be approximated in a separable form [16]

$$
I_{\mathrm{w}}=I_{2} \cdot f(w),
$$

where $I_{2}$ embraces only the effect of the vehicle configuration and location and type of estimated vibration response for the value $w=2$, while $f(w)\left[\mathrm{rad}^{-w+2} \mathrm{~s}^{w-2}\right]$ is a function of waviness only. Simultaneously for $f(w)$ the following approximation relationship was established

$$
f(w)=I_{\mathrm{w}} / I_{2}=\exp \left[A_{1} \Delta w+A_{2}(\Delta w)^{2}\right], \text { where } \Delta w=w-2 .
$$

Combining Eqs (4), (6), and (7), we obtain

$$
D_{\mathrm{A}}(w)=C I_{2} f(w) v^{w-1},
$$

where the influence of waviness on the response variance $D_{\mathrm{A}}$ is given by the product $f(w) v^{w-1}\left[\mathrm{rad}^{-w+2} \mathrm{~m}^{w-1} \mathrm{~s}^{-1}\right]$. While $f(w)$ decreases, $v^{w-1}$ being dependent also on $v$, is increasing. The effects of both components partially eliminate but in the summary result, the influence of waviness is remarkable especially for high speeds (see Fig. 3).

As the standard reference value of waviness, $w=2$ has been chosen. This is the simplest case of the $G_{\mathrm{H}}(\Omega)$ which means that for the elevation slope $H^{\prime}(l)=d H(l) / d l$, its PSD $G_{H^{\prime}}(\Omega)=C$, i.e. has character of a white noise. The same holds for the PSD of the wavelength $L$. Also, the road classification scheme based on $C$, proposed in ISO 8608 Standard considers $w=2$. This property significantly simplifies analytical solution of vibration tasks of both vehicle and pavement and enables analytical solution of relevant problems in the time domain, as well. Consequently, necessary corrections are related to the difference $\Delta w=w-2$.

Expressing the acceleration response variance $D_{\mathrm{A}}(w)$ for $w=2$ as

$$
D_{\mathrm{A}}(2)=C \cdot I_{2} \cdot v
$$

and applying the correction for $w \neq 2$ using the factor $K_{\mathrm{w}}, D_{\mathrm{A}}(w)=K_{\mathrm{w}} \cdot D_{\mathrm{A}}(2)$, i.e. inserting for $D_{\mathrm{A}}(w)$ and $D_{\mathrm{A}}(2)$ from (8) and (8a), respectively, then $C \cdot I_{2} \cdot f(w) \cdot v^{w-1}=K_{\mathrm{w}} \cdot C \cdot I_{2} \cdot v$ and we obtain

$$
K_{\mathrm{w}}=f(w) \cdot v^{w-2}
$$

with the dimension [ $\mathrm{rad}^{-w+2} \mathrm{~m}^{w-2}$ ]. Evidently for $\Delta w=w-2, K_{\mathrm{w}}=1$ not only numerically but $K_{\mathrm{w}}$ takes the character of a dimensionless quantity.

After inserting for $f(w)$ from Eq. (7), the correction factor $K_{\mathrm{w}}$ expresses in the form

$$
K_{\mathrm{w}}=\exp \left[A_{1} \Delta w+A_{2}(\Delta w)^{2}\right] v^{\Delta w} .
$$




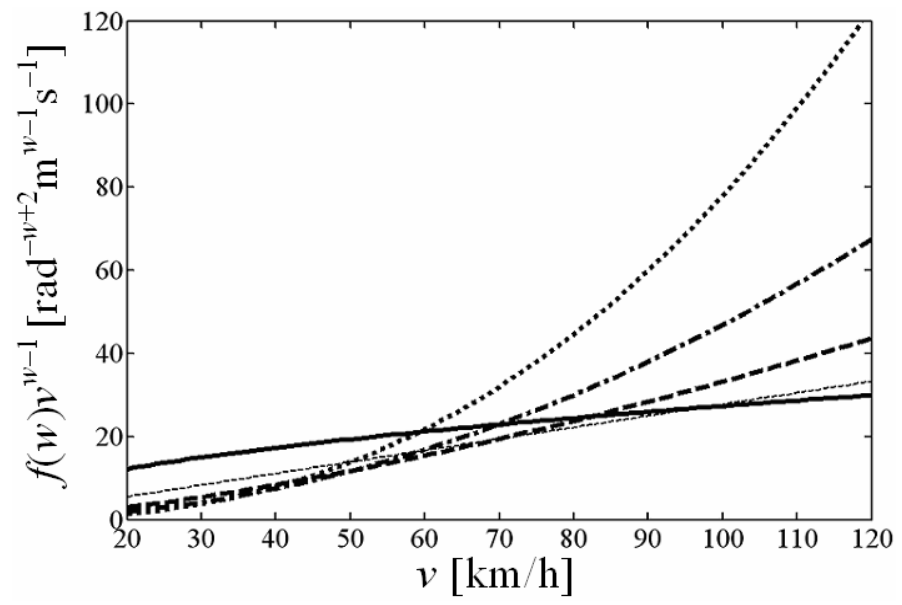

Fig. 3. The function $f(w) v^{w-1}\left(A_{1}=-3.04, A_{2}=0.227\right)$ in dependence on travel speed and waviness $(w=1.5(-), 2(--), 2.5(--)$, 3 (-•-), $3.5(\bullet \bullet))$.

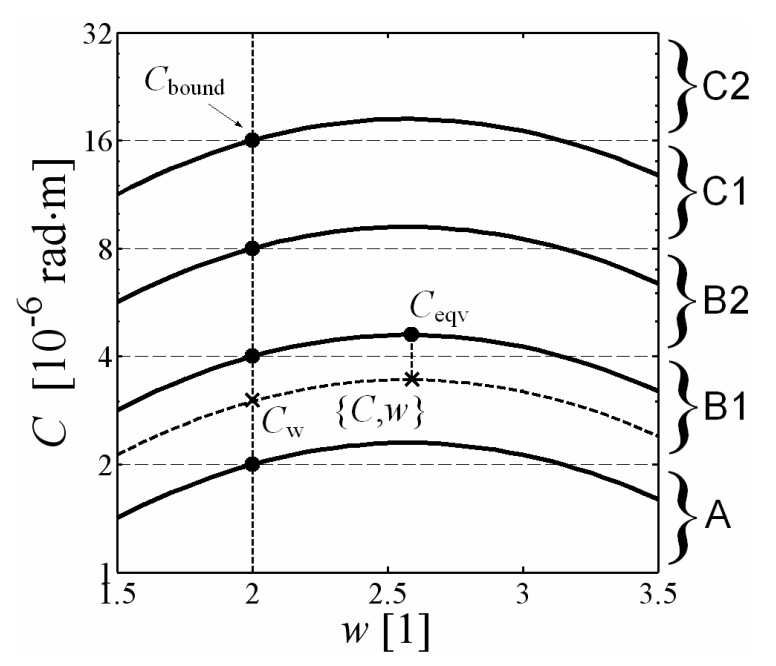

Fig. 4. Indication of $C, w, C_{\mathrm{w}}, C_{\mathrm{bound}}, C_{\mathrm{eqv}}$ values in the unevenness index - waviness plane.

For the use of the correction factor $K_{\mathrm{w}}$, two approaches are possible.

The direct approach to the correction for the effect of waviness consists in evaluation of the corrected unevenness index $C_{\mathrm{w}}$ according to the relationship

$$
C_{\mathrm{w}}=K_{\mathrm{w}} \cdot C
$$

allowing to express the acceleration response for arbitrary waviness $D_{\mathrm{A}}(w)$ in the form

$$
D_{\mathrm{A}}(w)=C_{\mathrm{w}} \cdot I_{\mathrm{w}} \cdot v \text {. }
$$

The interpretation of the $C_{\mathrm{w}}$ value is the following (Fig. 4): The evaluated road profile section described with a pair of PSD parameters, $\{C, w\}$, has the same influence on the vibration response variance as the profile section characterized by a pair $\left\{C_{\mathrm{w}}, w=2\right\}$ with $C_{\mathrm{w}}$ calculated according to Eq. (11). The value of the corrected unevenness index $C_{\mathrm{w}}$ is used when assessing the road quality according to some applied scaling or verbally defined valuation system, such as e.g. the Table C.2 in ISO 8608 (see also Table A1), or when incorporating it into some more general pavement performance ability indicator. This approach is addressed in detail in Section 4 and Appendix 3. The visualization of introduced quantities is presented in Fig. 4 . The net of boundary values $C_{\text {bound }}$ between individual 


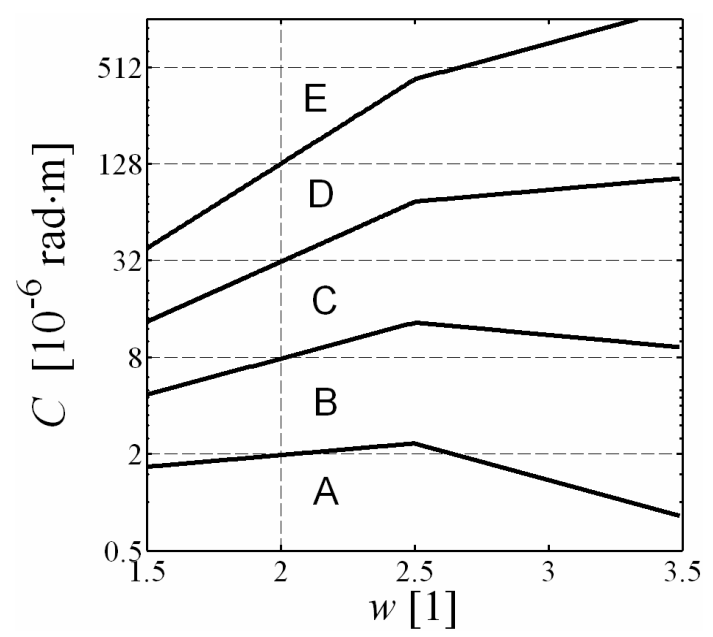

Fig. 5. Visualization of the SEI classification scheme in comparison with the ISO 8608 proposal.

road classes (here used halved ISO 8608 classes, i.e. $2,4,8,16,32$ ) is drawn with thin horizontal dashed lines and the relation between $\{C, w\}$ and $\left\{C_{\mathrm{w}}, w=2\right)$ is indicated.

In this figure, the inverse approach to this task is also enlightened. Instead of correcting the measured value $C$ according to Eq. (11), the correction is applied to the boundary values $C_{\text {bound }}$ of the valuation frame using the inverse value of $K_{\mathrm{w}}$ giving an equivalent criterion value $C_{\mathrm{eqv}}=C_{\mathrm{bound}} / K_{\mathrm{w}}$. Thus, a system of convex curves (drawn thick) forming the $\left(C_{\text {eqv }}-w\right)$ plane is obtained, into which the both originally measured variables $C, w$ are inserted to obtain the corresponding verbally denominated quality class. Evidently, both approaches are equivalent because the relations $C_{\mathrm{w}} / C_{\mathrm{bound}}$ and $C / C_{\mathrm{eqv}}$ are the same.

An other example of the inverse approach is given in [4] where a single-number unevenness indicator $S E I$ (Spektraler Ebenheits-Index) is defined as follows

$$
S E I= \begin{cases}C^{1 / w} & \text { for } w \leqslant 2.5 \\ 4(C / 32)^{1 / w} & \text { for } w \geqslant 2.5\end{cases}
$$

which is visualized in Fig. 5 with solid lines. The ISO boundary lines are also plotted as thin horizontal dashed lines. Note the mutual coincidence of both systems at $w=2$. The $S E I$ definition is based on assuming the effects of road unevenness on the travel safety, pavement loading, travel comfort and freight loading. Three road categories are considered: motorways with travel speeds $180 \mathrm{~km} / \mathrm{h}$ for personal cars and $80 \mathrm{~km} / \mathrm{h}$ for trucks, highways with travel speeds $100 \mathrm{~km} / \mathrm{h}$ for personal cars and $80 \mathrm{~km} / \mathrm{h}$ for trucks, and local roads with $50 \mathrm{~km} / \mathrm{h}$ for both personal cars and trucks. Although this proposal is very well founded and elaborated, it seems that it is less suitable for the use in the road management practice when compared with the direct approach presented in Section 4 and Appendix 3. A comparison of $S E I$ with the (inversely formulated) approach using $K_{\mathrm{w}}$ given in [16] shows a fairly good mutual agreement for high-quality roads.

\section{Estimation of the correction factor $K_{\mathrm{w}}$ and its parameters $A_{1}$ and $A_{2}$}

For the estimation of the correction factor $K_{\mathrm{w}}$ the corresponding parameters $A_{1}, A_{2}$ must be determined first. For particular vibration responses the integrated transfers (Eq. (5)) in the frequency range from 0 to $30 \mathrm{~Hz}$ for the waviness interval $w$ from 1.5 to 3.5 with step 0.1 (shortly denoted as $w=1.5(0.1) 3.5$ ) were calculated and their fitting with function $f(w)$ (Eq. (7)) were provided. Following values of parameters $A_{1}, A_{2}$ were obtained for two vehicle models (Appendix 2) and particular responses:

- Passenger car model (Fig. A1):

$A_{1}=-3.04 ; A_{2}=0.227$ - driver's seat frequency weighted vertical acceleration, $a_{\mathrm{wds}}$; 
$A_{1}=-3.21 ; A_{2}=0.302$ - passenger's seat frequency weighted vertical acceleration, $a_{\mathrm{wps}}$;

$A_{1}=-3.35 ; A_{2}=0.545$ - car body vertical acceleration (CG of the mass $\left.m_{2}\right), a_{\mathrm{cb}}$;

$A_{1}=-4.04 ; A_{2}=0.478-$ front axle wheel dynamic tyre force, $F_{\mathrm{df}}$;

$A_{1}=-4.14 ; A_{2}=0.531-$ rear axle wheel dynamic tyre force, $F_{\mathrm{dr}}$;

- Truck model (Fig. A2):

$A_{1}=-3.57 ; A_{2}=0.136$ - driver's body frequency weighted vertical acceleration, $a_{\mathrm{wd}}$;

$A_{1}=-3.30 ; A_{2}=0.471-$ car body vertical acceleration (CG of mass $\left.m_{4}\right), a_{\mathrm{cb}}$;

$A_{1}=-3.93 ; A_{2}=0.244-$ front axle wheel dynamic tyre force, $F_{\mathrm{d} 1}$;

$A_{1}=-3.88 ; A_{2}=0.416-$ driven axle wheel dynamic tyre force, $F_{\mathrm{d} 2}$;

$A_{1}=-3.91 ; A_{2}=0.252-$ rear axle wheel dynamic tyre force, $F_{\mathrm{d} 3}$.

Abovementioned values should lead to the constant RMS values of vibration response independent on waviness for particular responses, for example using of values $A_{1}=-3.04 ; A_{2}=0.227$ should cause the constant acceleration response, $a_{\text {wds }}$ (see Fig. 6).

For the frequency weighting of simulated acceleration responses, the filter $W_{k}$ intended for vertical acceleration on the seat surface defined in the standard ISO 2631-1: 1997 [11] was used. A short information on $W_{k}$ is given in Appendix 1. All computations were provided in Matlab ${ }^{\circledR}$ environment.

Further, a new variable for the range of particular responses, $R$, was introduced for estimation of changes in vibration response in dependence on waviness. The range of particular responses is estimated for chosen nine waviness levels $w=1.5(0.25) 3.5$ as

$$
R[y]=\max (\operatorname{RMS}\{y\})-\min (\operatorname{RMS}\{y\}),
$$

where $y$ is a common generalised denomination for all considered vibration responses of the vehicle model. The response RMS values have been calculated in a frequency domain from the spectral densities in accordance with the theory given e.g. in $[5,19]$. Denotation $R_{\mathrm{ABS}}$ is used for responses caused by road profiles with constant value of unevenness index $C=1 \times 10^{-6} \mathrm{rad}$ m independent on waviness, $w$. In opposite, denotation $R_{\mathrm{EQV}}$ is used for responses caused by road profiles with variable value of unevenness index $C_{\text {eqv }}\left(=C / K_{\mathrm{w}}\right)$, which is dependent on waviness $w$.

In Fig. 6(a) the RMS values of driver's seat acceleration response $a_{\text {wds }}$ of a passenger car in dependence on waviness are presented. It is clear, that for suitably set-up of parameters $A_{1}$ and $A_{2}$ (or $C_{\text {eqv }}$ values) the constant response level independent on waviness may be achieved. The constant value of $C=1 \times 10^{-6} \mathrm{rad} \mathrm{m}$ causes the range $R_{\mathrm{ABS}}\left[a_{\mathrm{wds}}\right]=0.187 \mathrm{~m} / \mathrm{s}^{2}$ while for $C_{\text {eqv }}$ the corresponding value of similarly defined range $R_{\mathrm{EQV}}\left[a_{\mathrm{wds}}\right]=$ $0.001 \mathrm{~m} / \mathrm{s}^{2}$ was obtained. Examples of these ranges are visually pointed up in Fig. 6(a), 6(c) and 6(e).

In Fig. 6(b) to 6(e), the RMS values are presented for the remaining four responses considered for the passenger car where the $A_{1}, A_{2}$ parameters are left the same as in the case 6(a). Evidently, with increasing differences of $A_{1}$, $A_{2}$ parameters for the set-up case (a) and the remaining (b) to (e) ones, RMS differences increase in an unacceptable extent. This appears very distinctly for dynamic tyre forces (cases (d) and (e)), where even $R_{\mathrm{EQV}}>R_{\mathrm{ABS}}$. Therefore, a procedure for optimising $A_{1}, A_{2}$ values must be provided leading to acceptable differences for all selected responses simultaneously.

For the reduction estimation of the response range in the case of using the approach of equivalent unevenness index $C_{\text {eqv }}=C_{\mathrm{bound}} / K_{\mathrm{w}}$, the relative change of range, $\delta$, has been introduced which is defined as

$$
\delta[y]=\frac{R_{\mathrm{EQV}}[y]}{R_{\mathrm{ABS}}[y]} \times 100 \% .
$$

The main purpose of this study is to find optimised values of $A_{1}$ and $A_{2}$ parameters, which take into account all the relevant vibration responses for two typical vehicles and three different vehicle speeds.

For the estimation of optimised values of $A_{1}$ and $A_{2}$ parameters the following four limitations have been fulfilled:

(1) The ranges of vibration response RMS values were estimated in the range of waviness, $w=1.5-3.5$.

(2) The range of any vibration response RMS values should be not larger than that one calculated for constant unevenness index $C$ value (i.e. $R_{\mathrm{EQV}}<R_{\mathrm{ABS}}$, or $\delta[y]<100 \%$ ).

(3) The parameters $A_{1}, A_{2}$ should reflect the vibration response of passenger car and truck at the same time (the models parameters used are presented in Appendix 2). 


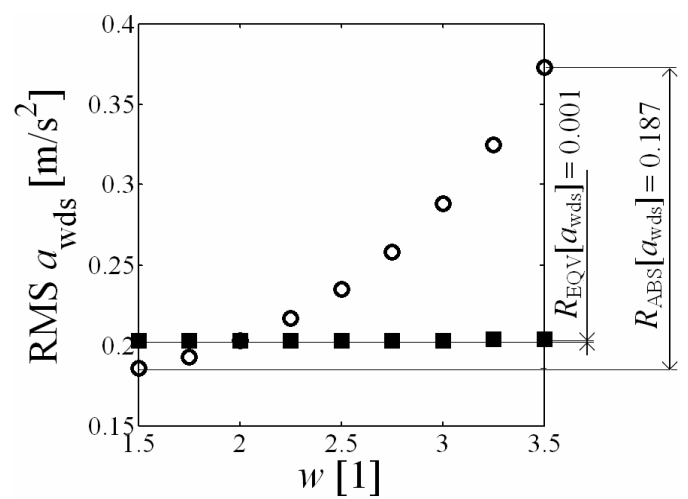

(a)

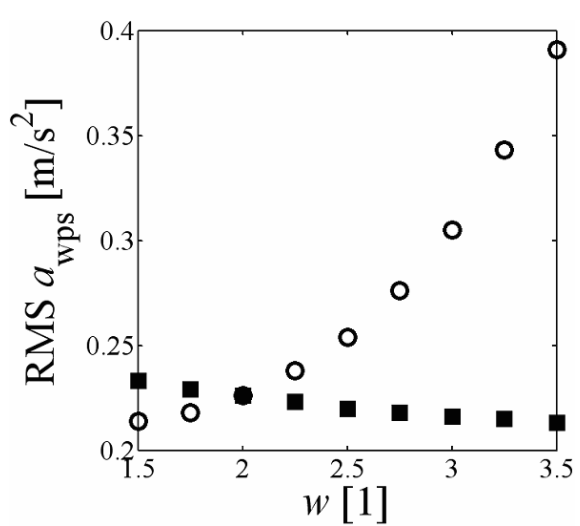

(b)

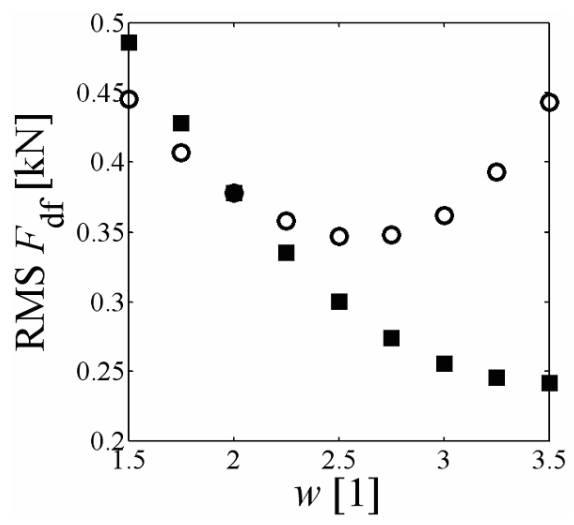

(d)

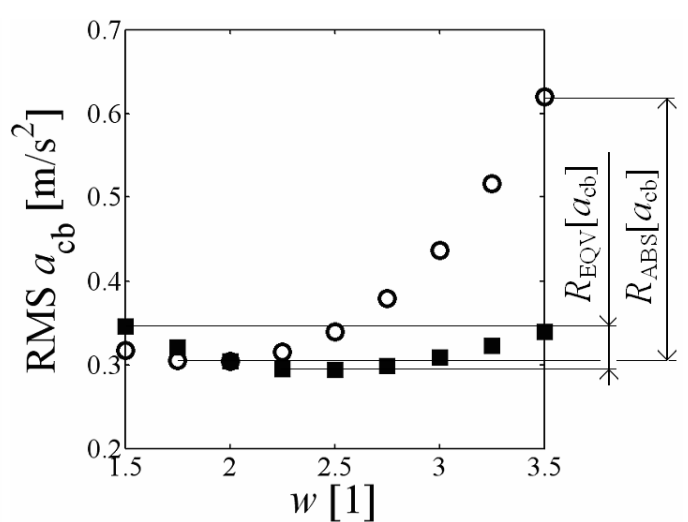

(c)

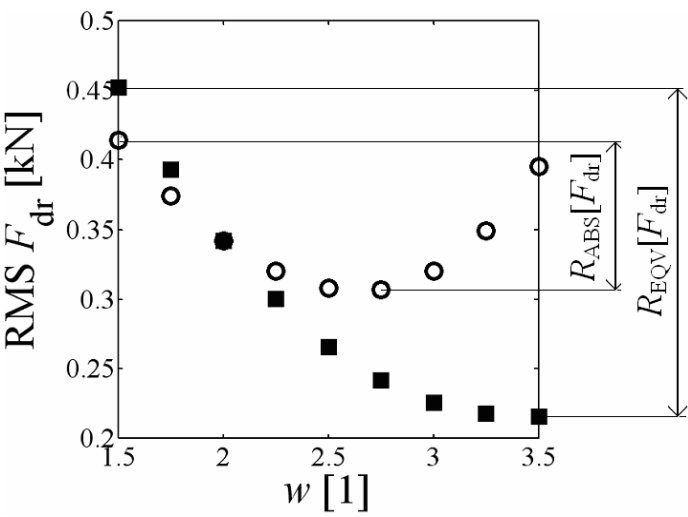

(e)

Fig. 6. The estimation of range of various responses for a passenger car model and $v=120 \mathrm{~km} / \mathrm{h}, A_{1}=-3.04 ; A_{2}=0.227$ : (a) frequency weighted acceleration of driver's seat, $a_{\mathrm{wds}}$; (b) frequency weighted acceleration of passenger's seat, $a_{\mathrm{wps}}$; (c) vertical acceleration of car body, $a_{\mathrm{cb}}$; (d) front axle wheel dynamic tyre force, $F_{\mathrm{df}}$; (e) rear axle wheel dynamic tyre force, $F_{\mathrm{dr}}\left(\bigcirc-\right.$ constant excitation, $C=1 \times 10^{-6}$ rad m; - variable excitation, $\left.C_{\text {eqv }}=C / K_{\mathrm{w}}\right)$.

(4) The following main criteria of the vehicle response are considered:
(a) ride comfort;
(b) dynamic load of pavement;
(c) load comfort. 


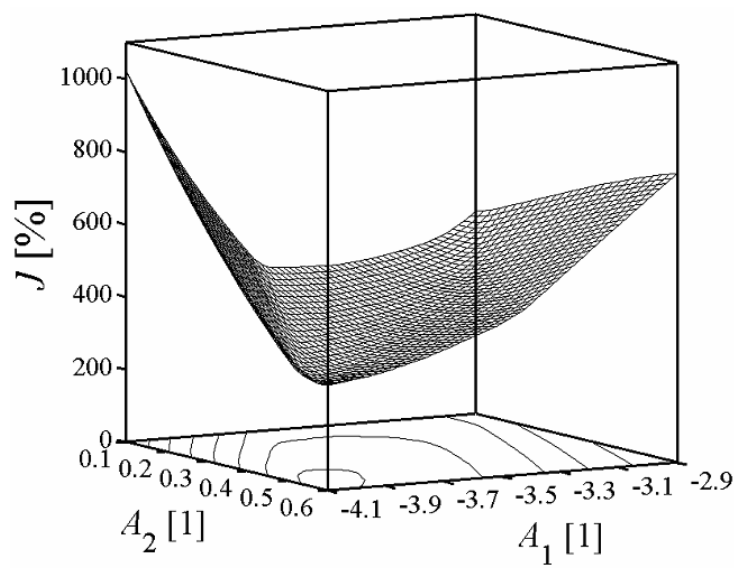

(a)

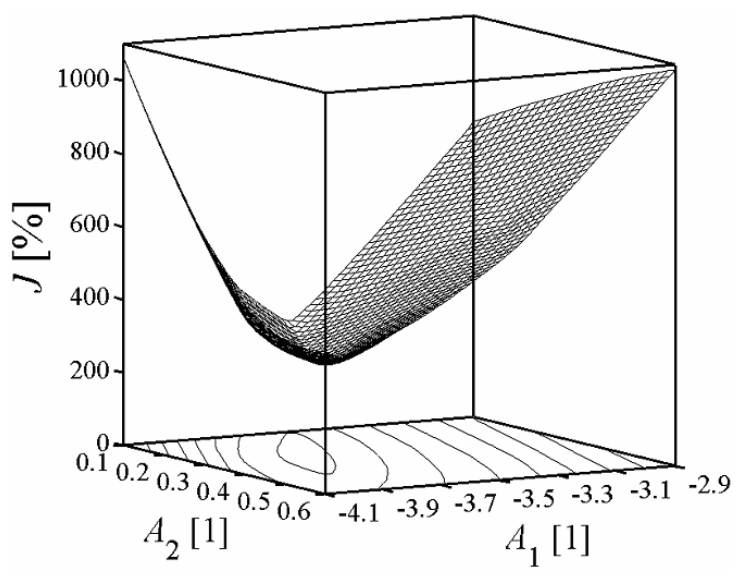

(b)

Fig. 7. Objective function $J\left(A_{1}, A_{2}\right)$ : (a) passenger car model, $v=120 \mathrm{~km} / \mathrm{h}, A_{1 \mathrm{opt}}=-4.04, A_{2 \mathrm{opt}}=0.54$; (b) truck model, $v=90 \mathrm{~km} / \mathrm{h}$, $A_{1 \mathrm{opt}}=-3.66, A_{2 \mathrm{opt}}=0.34$.

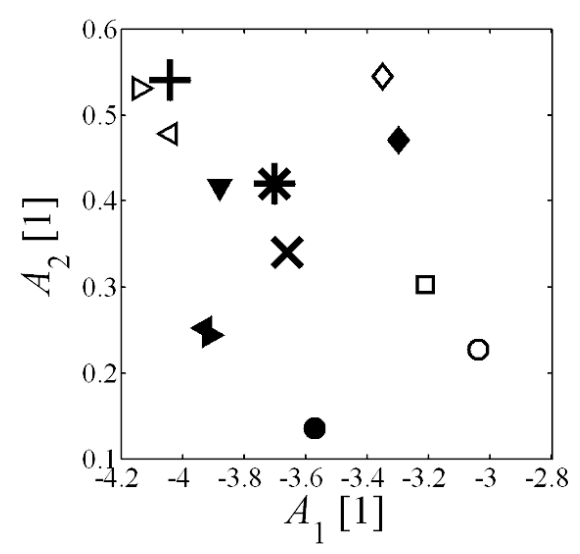

Fig. 8. Calculated and optimised values of $A_{1}$ and $A_{2}$ parameters for particular vibration responses: Calculated values: Passenger car \& $120 \mathrm{~km} / \mathrm{h}: a_{\mathrm{wds}}(\bigcirc), a_{\mathrm{wps}}(\square), a_{\mathrm{cb}}(\diamond), F_{\mathrm{df}}(\triangleright), F_{\mathrm{dr}}(\triangleleft)$; Truck \& $90 \mathrm{~km} / \mathrm{h}: a_{\mathrm{wd}}(\bullet), a_{\mathrm{cb}}(\diamond), F_{\mathrm{d} 1}(\triangleright), F_{\mathrm{d} 2}(\nabla), F_{\mathrm{d} 3}(\triangleleft) ;$ Optimised values: Passenger car \& $120 \mathrm{~km} / \mathrm{h}(+)$, Truck \& $90 \mathrm{~km} / \mathrm{h}(\times)$, Passenger car + Truck, $90 \mathrm{~km} / \mathrm{h}(*)$.

The optimised values of $A_{1 \mathrm{opt}}$ and $A_{2 \mathrm{opt}}$ are determined as a minimum of the objective functions $J$ in the considered bands of $A_{1}=-4.1(0.02)-2.9$ and $A_{2}=0.1(0.02) 0.6$, which cover the above-mentioned typical values obtained for any of the considered vibration responses.

The objective functions $J$ have been defined as follows:

- for the passenger car model:

$$
J\left(A_{1}, A_{2}\right)=\delta\left[a_{\mathrm{wds}}\right]+\delta\left[a_{\mathrm{wps}}\right]+\delta\left[a_{\mathrm{cb}}\right]+\delta\left[F_{\mathrm{df}}\right]+\delta\left[F_{\mathrm{dr}}\right] \rightarrow \min ;
$$

- for the truck model:

$$
J\left(A_{1}, A_{2}\right)=\delta\left[a_{\mathrm{wd}}\right]+\delta\left[a_{\mathrm{cb}}\right]+\delta\left[F_{\mathrm{d} 1}\right]+\delta\left[F_{\mathrm{d} 2}\right]+\delta\left[F_{\mathrm{d} 3}\right] \rightarrow \min
$$

- for the combination of both car models:

$$
\begin{aligned}
J\left(A_{1}, A_{2}\right)= & \delta\left[a_{\mathrm{wds}}\right]+\delta\left[a_{\mathrm{wps}}\right]+\delta\left[a_{\mathrm{cb}}\right]+\delta\left[F_{\mathrm{df}}\right]+\delta\left[F_{\mathrm{dr}}\right] \\
& +\delta\left[a_{\mathrm{wd}}\right]+\delta\left[a_{\mathrm{cb}}\right]+\delta\left[F_{\mathrm{d} 1}\right]+\delta\left[F_{\mathrm{d} 2}\right]+\delta\left[F_{\mathrm{d} 3}\right] \rightarrow \min .
\end{aligned}
$$

The shapes of obtained objective functions $J$ for both vehicle models are presented in Fig. 7. In Fig. 8, the pairs of calculated and optimised $A_{1}$ and $A_{2}$ values for selected response variables are given. 
Table 1

Optimised values of $A_{1 \mathrm{opt}}$ and $A_{2 \mathrm{opt}}$ and reduction of particular responses $\delta[$.$] for three travel speeds$

\begin{tabular}{|c|c|c|c|c|c|c|c|c|c|}
\hline Car model & $v[\mathrm{~km} / \mathrm{h}]$ & $A_{\text {lopt }[1]}$ & $A_{2 o p t}[1]$ & $J_{\min }[\%]$ & & & $\delta[].[\%]$ & & \\
\hline \multirow{2}{*}{ PAS } & \multirow{8}{*}{60} & \multirow{2}{*}{-3.28} & \multirow{2}{*}{0.32} & \multirow{2}{*}{210.9} & $\delta\left[a_{\mathrm{wds}}\right]$ & $\delta\left[a_{\mathrm{wps}}\right]$ & $\delta\left[a_{\mathrm{cb}}\right]$ & $\delta\left[F_{\mathrm{df}}\right]$ & $\delta\left[F_{\mathrm{dr}}\right]$ \\
\hline & & & & & 25.93 & 13.51 & 30.49 & 70.26 & 70.74 \\
\hline \multirow{2}{*}{ TRUCK } & & \multirow{2}{*}{-3.64} & \multirow{2}{*}{0.34} & \multirow{2}{*}{234.9} & $\delta\left[a_{\mathrm{wd}}\right]$ & $\delta\left[a_{\mathrm{cb}}\right]$ & $\delta\left[F_{\mathrm{d} 1}\right]$ & $\delta\left[F_{\mathrm{d} 2}\right]$ & $\delta\left[F_{\mathrm{d} 3}\right]$ \\
\hline & & & & & 28.85 & 96.3 & 42.62 & 35.91 & 31.23 \\
\hline \multirow{4}{*}{$\mathrm{PAS}+\mathrm{TRUCK}$} & & \multirow{4}{*}{-3.36} & \multirow{4}{*}{0.38} & \multirow{2}{*}{222.4} & $\delta\left[a_{\mathrm{wds}}\right]$ & $\delta\left[a_{\mathrm{wps}}\right]$ & $\delta\left[a_{\mathrm{cb}}\right]$ & $\delta\left[F_{\mathrm{df}}\right]$ & $\delta\left[F_{\mathrm{dr}}\right]$ \\
\hline & & & & & 37.04 & 29.73 & 21.95 & 66.67 & 67.02 \\
\hline & & & & \multirow{2}{*}{289.1} & $\delta\left[a_{\mathrm{wd}}\right]$ & $\delta\left[a_{\mathrm{cb}}\right]$ & $\delta\left[F_{\mathrm{d} 1}\right]$ & $\delta\left[F_{\mathrm{d} 2}\right]$ & $\delta\left[F_{\mathrm{d} 3}\right]$ \\
\hline & & & & & 65.87 & 12.96 & 72.24 & 70.19 & 67.88 \\
\hline \multirow{2}{*}{ PAS } & \multirow{8}{*}{90} & \multirow{2}{*}{-3.46} & \multirow{2}{*}{0.44} & \multirow{2}{*}{287} & $\delta\left[a_{\mathrm{wds}}\right]$ & $\delta\left[a_{\mathrm{wps}}\right]$ & $\delta\left[a_{\mathrm{cb}}\right]$ & $\delta\left[F_{\mathrm{df}}\right]$ & $\delta\left[F_{\mathrm{dr}}\right]$ \\
\hline & & & & & 39.74 & 35.14 & 14.89 & 100 & 97.26 \\
\hline \multirow{2}{*}{ TRUCK } & & \multirow{2}{*}{-3.66} & \multirow{2}{*}{0.34} & \multirow{2}{*}{333} & $\delta\left[a_{\mathrm{wd}}\right]$ & $\delta\left[a_{\mathrm{cb}}\right]$ & $\delta\left[F_{\mathrm{d} 1}\right]$ & $\delta\left[F_{\mathrm{d} 2}\right]$ & $\delta\left[F_{\mathrm{d} 3}\right]$ \\
\hline & & & & & 70.75 & 99.21 & 64.88 & 35.67 & 62.44 \\
\hline \multirow{4}{*}{$\mathrm{PAS}+\mathrm{TRUCK}$} & & \multirow{4}{*}{-3.7} & \multirow{4}{*}{0.42} & \multirow{2}{*}{366.3} & $\delta\left[a_{\mathrm{wds}}\right]$ & $\delta\left[a_{\mathrm{wps}}\right]$ & $\delta\left[a_{\mathrm{cb}}\right]$ & $\delta\left[F_{\mathrm{df}}\right]$ & $\delta\left[F_{\mathrm{dr}}\right]$ \\
\hline & & & & & 97.44 & 95.95 & 68.79 & 50.69 & 53.42 \\
\hline & & & & \multirow{2}{*}{366} & $\delta\left[a_{\mathrm{wd}}\right]$ & $\delta\left[a_{\mathrm{cb}}\right]$ & $\delta\left[F_{\mathrm{d} 1}\right]$ & $\delta\left[F_{\mathrm{d} 2}\right]$ & $\delta\left[F_{\mathrm{d} 3}\right]$ \\
\hline & & & & & 95.28 & 88.1 & 71.5 & 40.87 & 70.25 \\
\hline \multirow{2}{*}{ PAS } & \multirow{8}{*}{120} & \multirow{2}{*}{-4.04} & \multirow{2}{*}{0.54} & & $\delta\left[a_{\mathrm{wds}}\right]$ & $\delta\left[a_{\mathrm{wps}}\right]$ & $\delta\left[a_{\mathrm{cb}}\right]$ & $\delta\left[F_{\mathrm{df}}\right]$ & $\delta\left[F_{\mathrm{dr}}\right]$ \\
\hline & & & & 281.8 & 80.75 & 80.79 & 77.46 & 19.39 & 23.36 \\
\hline & & & & & $\delta\left[a_{\mathrm{wd}}\right]$ & $\delta\left[a_{\mathrm{cb}}\right]$ & $\delta\left[F_{\mathrm{d} 1}\right]$ & $\delta\left[F_{\mathrm{d} 2}\right]$ & $\delta\left[F_{\mathrm{d} 3}\right]$ \\
\hline TRUCK & & -3.8 & 0.38 & 259.4 & 69.8 & 76.56 & 70.07 & 20.75 & 22.19 \\
\hline & & & & & $\delta\left[a_{\mathrm{wds}}\right]$ & $\delta\left[a_{\mathrm{wps}}\right]$ & $\delta\left[a_{\mathrm{cb}}\right]$ & $\delta\left[F_{\mathrm{df}}\right]$ & $\delta\left[F_{\mathrm{dr}}\right]$ \\
\hline & & & & 301.8 & 69.52 & 67.8 & 66.35 & 44.9 & 53.27 \\
\hline PAS + TRUCK & & -3.84 & 0.44 & & $\delta\left[a_{\mathrm{wd}}\right]$ & $\delta\left[a_{\mathrm{cb}}\right]$ & $\delta\left[F_{\mathrm{d} 1}\right]$ & $\delta\left[F_{\mathrm{d} 2}\right]$ & $\delta\left[F_{\mathrm{d} 3}\right]$ \\
\hline & & & & 265.2 & 73.15 & 72.7 & 82.19 & 14.17 & 22.98 \\
\hline
\end{tabular}

The summary of optimised values $A_{1 \mathrm{opt}}$ and $A_{2 \mathrm{opt}}$ as well as the corresponding percentage reductions (Eq. (13)) of particular responses are introduced in Table 1. Three typical travel speeds have been considered: $v=60,90$ and $120 \mathrm{~km} / \mathrm{h}$. Based on results presented in Table 1 it may be stated that usually it is possible to reduce all the followed responses considerably at the same time. The optimisation results in Table 1 revealed that it is possible to find a suitable pair of $A_{1}$ and $A_{2}$ parameters that causes at the same time a lower vibration range than the range obtained by ignoring waviness, i.e. $\delta<100 \%$ for all ten followed vibration responses for two distinctly different vehicle models.

\section{Proposal of a road classification scheme considering both the unevenness index $C$ and waviness $w$ and the vehicle response}

When processing measured longitudinal road profile $h(l)$ according to ISO 8608 [10] or EN 13036-5 [9], estimates of parameters $C$ and $w$ of its PSD $G_{\mathrm{H}}(\Omega)$ are evaluated.

Reflecting the results presented in Sections 2 and 3, a verbally classification scheme for the longitudinal road unevenness assessment is summarized in Appendix 3.

On this place, the most important reasons and standpoints for this final presentation are given below:

1. As the basic classification frame, Table C.2 of ISO 8608 has been assumed but with a small modification consisting in (geometric) halving each class width used there for the following reason. It follows from practical experience that the logarithmic scaling with the quotient $q=4$ is too course especially for high quality roads. This position is supported by another ISO standard ISO 2631-1 [11], (see also Appendix 1, Table A2) considering the scaling of comfort sensing of seated man to vertical vibration acceleration. Here, the scaling quotient is $q=1.6$, which for $C$ (being proportional to the unevenness variance) makes $q=2.56$. The rounding down to 2 enables to keep the alphabetical denomination of classes of ISO 8608 when adding supplementary distinguishing numbers 1 and 2. In [4], when comparing the SEI classification with the ISO 8608 one, the halving of the ISO 8608 classes was also applied. 
Table 2

Values of the correction factor $K_{\mathrm{W}}$ : (a) personal car model; (b) truck model; (c) combination of personal car model and truck model

\begin{tabular}{|c|c|c|c|c|c|c|c|c|c|c|c|c|c|c|c|c|c|c|}
\hline & $A_{1}[1]$ & $A_{2}[1]$ & & & & & & & & (a) $\mathrm{Pel}$ & rsonal & & & & & & & \\
\hline$w[1]$ & & & 1.5 & 1.6 & 1.7 & 1.8 & 1.9 & 2 & 2.1 & 2.2 & 2.3 & 2.4 & 2.5 & 2.6 & 2.7 & 2.8 & 2.9 & 3 \\
\hline $60 \mathrm{~km} / \mathrm{h}$ & -3.28 & 0.32 & 1.368 & 1.269 & 1.184 & 1.112 & 1.051 & 1 & 0.957 & 0.923 & 0.895 & 0.873 & 0.858 & 0.848 & 0.844 & 0.845 & 0.852 & 0.864 \\
\hline $90 \mathrm{~km} / \mathrm{h}$ & -3.46 & 0.44 & 1.259 & 1.182 & 1.118 & 1.068 & 1.029 & 1 & 0.98 & 0.97 & 0.968 & 0.974 & 0.989 & 1.014 & 1.048 & 1.093 & 1.15 & 1.22 \\
\hline $120 \mathrm{~km} / \mathrm{h}$ & -4.04 & 0.54 & 1.494 & 1.35 & 1.232 & 1.137 & 1.061 & 1 & 0.953 & 0.918 & 0.895 & 0.881 & 0.877 & 0.882 & 0.897 & 0.922 & 0.958 & 1.007 \\
\hline & & & \multicolumn{16}{|c|}{ (b) Truck } \\
\hline $60 \mathrm{~km} / \mathrm{h}$ & -3.64 & 0.34 & 1.646 & 1.47 & 1.321 & 1.196 & 1.09 & 1 & 0.924 & 0.859 & 0.805 & 0.759 & 0.72 & 0.688 & 0.662 & 0.642 & 0.626 & 0.615 \\
\hline $90 \mathrm{~km} / \mathrm{h}$ & -3.66 & 0.34 & 1.357 & 1.26 & 1.177 & 1.107 & 1.049 & 1 & 0.96 & 0.928 & 0.903 & 0.885 & 0.873 & 0.867 & 0.867 & 0.873 & 0.885 & 0.904 \\
\hline \multirow[t]{2}{*}{$120 \mathrm{~km} / \mathrm{h}$} & -3.8 & 0.38 & 1.273 & 1.195 & 1.13 & 1.077 & 1.034 & 1 & 0.975 & 0.957 & 0.948 & 0.945 & 0.95 & 0.961 & 0.981 & 1.008 & 1.045 & 1.09 \\
\hline & & & \multicolumn{16}{|c|}{ (c) Personal car and Truck } \\
\hline $60 \mathrm{~km} / \mathrm{h}$ & -3.36 & 0.38 & 1.445 & 1.322 & 1.219 & 1.133 & 1.06 & 1 & 0.95 & 0.91 & 0.878 & 0.854 & 0.837 & 0.826 & 0.822 & 0.824 & 0.832 & 0.847 \\
\hline $90 \mathrm{~km} / \mathrm{h}$ & -3.70 & 0.42 & 1.413 & 1.296 & 1.2 & 1.12 & 1.054 & 1 & 0.957 & 0.924 & 0.899 & 0.882 & 0.873 & 0.872 & 0.877 & 0.89 & 0.911 & 0.941 \\
\hline $120 \mathrm{~km} / \mathrm{h}$ & -3.84 & 0.44 & 1.319 & 1.226 & 1.15 & 1.088 & 1.038 & 1 & 0.971 & 0.952 & 0.941 & 0.939 & 0.945 & 0.959 & 0.982 & 1.015 & 1.058 & 1.112 \\
\hline
\end{tabular}

2. Three main road categories have been considered:

- motorways with the nominal travel speed $120 \mathrm{~km} / \mathrm{h}$,

- highways with the nominal travel speed $90 \mathrm{~km} / \mathrm{h}$, and

- local and urban roads with the nominal travel speed $60 \mathrm{~km} / \mathrm{h}$.

The nominal travel speed means that for these values, parameters necessary for establishing the correction factor $K_{\mathrm{w}}$ have been calculated with the hope that design or maximum permissible speeds of real roads will be only little different from the nominal ones. When desirable, other running speeds may be considered, as well. Following the results in Sections 2 and 3 the effect of waviness different from 2 is considered by using the correction factor $K_{\mathrm{w}}$ according to Eq. (11). For all the travel speed road categories relevant $K_{\mathrm{w}}$ values taken from Table 2(c) are used.

\section{Some consequences for the International Roughness Index}

As already mentioned in the Introduction, the up to date mostly used unevenness indicator is the International Roughness Index $(I R I)$. Its principle is shortly explained in Appendix 1.

It follows from detailed reasoning given in Section 3 that when assuming the response approach to the longitudinal road unevenness assessment, even when considering some standardised vehicle transfer (such as of the "golden car" in the case of $I R I[2,23]$ ) road waviness and travel speed must also be taken into account.

The present definition of IRI [2,23] considers the standard travel speed $80 \mathrm{~km} / \mathrm{h}$ and entirely neglects the effect of unevenness waviness displayed in Fig. 9 in spite of the fact that its value may be established using the evaluation program for $I R I$ running for a travel speed different from the standard value $v=80 \mathrm{~km} / \mathrm{h}$ [14]. Therefore the present definition of $I R I$ is not completely determined in relation to the mentioned important additional conditions, namely the vehicle travel speed and unevenness waviness. Considering the effect of the travel speed $v$ it was derived in [13] that for $w=2, I R I \sim v^{-0.5}$. Thus, for $v<80 \mathrm{~km} / \mathrm{h}$, the IRI slightly overestimates the effect of unevenness but for $v>80 \mathrm{~km} / \mathrm{h}$, i.e. for the high-speed tracks as economically most important components of the national road nets, the standard IRI considerably (up to at 30\%) underestimates the real detrimental effect of unevenness. This should be understood in such a way that for high travel speeds, considerably lower critical IRI values should be set down than for $v=80 \mathrm{~km} / \mathrm{h}$ in the same manner as for $C$ (Appendix 3). Otherwise, practically all the high-speed tracks will be assessed as excellent or very good and the discriminating property of the present IRI classification frames (where the boundary values for IRI usually move between 2 and 4, but current high-speed motorways manifest values below 1) will be lost. Concerning the effect of waviness for $v=120 \mathrm{~km} / \mathrm{h}, I R I$ is practically independent of $w$ in the mostly appearing interval of $w=2$ to 3 . Therefore, it may be found as practical, though only as a partial solution, to redefine the $I R I$ considering the travel speed $120 \mathrm{~km} / \mathrm{h}$ instead of the present value $80 \mathrm{~km} / \mathrm{h}$. For travel speeds $v<$ $120 \mathrm{~km} / \mathrm{h}$, the increasing waviness results in effective decreasing of $I R I$, for $v>120 \mathrm{~km} / \mathrm{h}$, the increasing waviness results in effective increasing of $I R I$. 


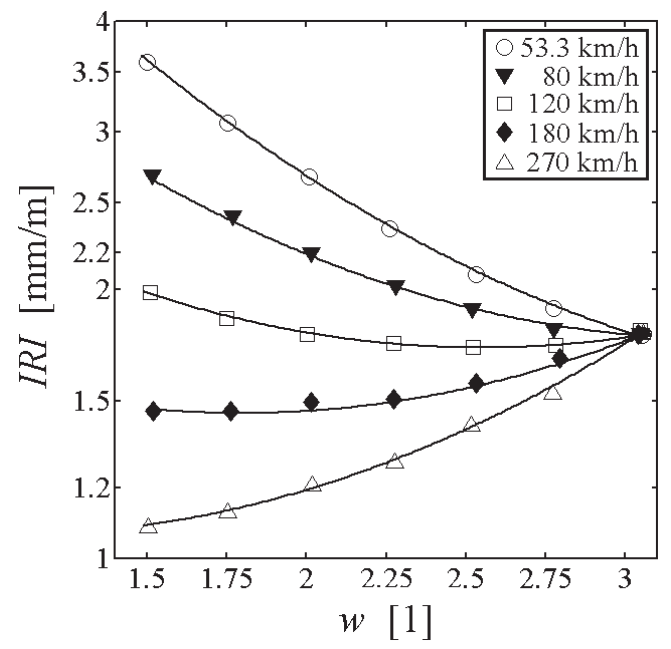

Fig. 9. The IRI dependence on waviness, $w$, and velocity, $v$ for $C=1 \times 10^{-6} \mathrm{rad}^{w-1} \mathrm{~m}^{3-w}$.

\section{Conclusions}

Based on various analytical and simulation results of the road-vehicle interaction the following main findings may be stated:

(1) The paper presents a novel approach to the road unevenness classification based on PSD with considering the vehicle vibration response and a broad interval of road waviness values.

(2) The results yield the comparison of vibration response between the 'absolute' classification of road unevenness (ISO 8608) with assumed waviness value $w=2$ and the proposed road classification with 'equivalent response' which takes the vehicle vibration response also into account. The presented results revealed the implications for the vehicle vibration response case if the road waviness in the road classification scheme (or its reducing to a fixed value, $w=2$ ) is ignored as it is assumed in the ISO 8608 standard.

(3) A complex simulation analysis for estimation of optimised values $A_{1}, A_{2}$ of correction factor $K_{\mathrm{w}}$ have been provided. The introduced factor $K_{\mathrm{w}}$ serves for the transformation of two basic parameters of the road profile elevation PSD $(C$ and $w)$ into a single-number indicator $C_{\mathrm{w}}$. For the optimisation purposes two planar models of vehicle (passenger car and truck), ten responses (reflecting ride comfort, dynamic load of road and cargo, ride safety) and three different vehicle speeds have been considered. The minimum of ten vibration response ranges sum in a broad waviness interval typical for real road sections ( $w=1.5$ to 3.5$)$ has been found for the correction factor $K_{\mathrm{w}}$ set-up.

(4) The optimisation has shown that it is possible to find a suitable setting of $A_{1}$ and $A_{2}$ parameters that causes a lower vibration range for all ten followed vibration responses at the same time on two different vehicle models than the range obtained by ignoring waviness.

(5) As the synthesis of the simulation results of road-vehicle interaction the proposal for the road classification has been introduced for three road categories (characterized by three various road design speeds). The values of the correction factor $K_{\mathrm{w}}$ are presented in detail in Table 2.

(6) The presented $C_{\mathrm{w}}$ indicator $\left(C_{\mathrm{w}}=K_{\mathrm{w}} C\right)$ may be a suitable alternative to the other commonly used singlenumber indicators as IRI, Ride Number, etc. Its applicability and advantages are demonstrated. The $C_{\mathrm{w}}$ indicator may be useful for simple comparison of road sections with arbitrary waviness $(w \neq 2)$ in accordance with the road classification in ISO 8608 which assumes a constant waviness $w=2$.

(7) The limitation of presented results is of course due to the simulation approach without verification of obtained results in real conditions. For example, an optimal setting of $A_{1}$ and $A_{2}$ parameters which cover the vibration responses of real vehicles of a broad vehicle family would be necessary. Obtained simulation results are necessary to be verified in real conditions on roads with different waviness values considering broad variety of vehicles. Thus, the presented road classification scheme should be considered as the first proposal of 
methodology, which incorporates the waviness into the road classification scheme. Also, the viability of the proposed standard should be checked during the probationary period of the preliminary accepted standard.

\section{Acknowledgement}

This work has been partially undertaken within the grant No. 2/6161/26 of the VEGA Grant agency of Slovak Academy of Sciences. The support of the Agency is gratefully acknowledged.

\section{Appendix 1}

Short characterization of standard ISO 8608: 1995 [10]

The purpose of the ISO 8608 Standard [10] is to facilitate the compilation and comparison of measured vertical road profile data from various sources (roads, highways, off-road terrain, etc.). It therefore specifies a uniform method of reporting data from one-track and multiple-track measurements. It specifies how measurements shall be reported, but not how the measurements shall be made.

In Annexes, selected partial items are discussed in more detail providing also recommended evaluation procedures. The Annex A presents an example of a report, which meets the minimum requirements of this standard. The Annex B ("Road profile characterization and PSD fitting") gives means of approximately characterizing specific road profiles in order to facilitate the division of road profiles into general classifications. A part of the road classification proposal is given in Table A1. A curve-fitting method is suggested for characterizing spectral data. Annex C provides general guidance for the use of road profile statistical data for simulation studies. Annex D discusses the processing of the power spectral density (PSD) with the Fast Fourier Transform (FFT) technique. A discussion on the statistical uncertainty of results is also given.

Table A1

Road classification proposal according to the ISO 8608 for $w=2[10]$

\begin{tabular}{cccc}
\hline Road class & \multicolumn{3}{c}{ Degree of roughness } \\
& $G_{\mathrm{H}}\left(\Omega_{0}\right)\left[10^{-6} \mathrm{~m}^{3} / \mathrm{rad}\right]\left(\Omega_{0}=1 \mathrm{rad} / \mathrm{m}\right)$ \\
\cline { 2 - 4 } & Lower limit & Geometric mean & Upper limit \\
\hline A & - & 1 & 2 \\
B & 2 & 4 & 8 \\
C & 8 & 16 & 32 \\
D & 32 & 64 & 128 \\
E & 128 & 256 & 512 \\
F & 512 & 1024 & 2048 \\
G & 2048 & 4096 & 8192 \\
H & 8192 & 16384 & - \\
\hline
\end{tabular}

Short characterization of standard ISO 2631-1: 1997 [11]

The ISO 2631-1 Standard [11] defines methods for the measurement of periodic, random and transient whole-body vibrations. For the comfort of seated persons this clause applies to the frequency range 0.5 to $80 \mathrm{~Hz}$, which occurs in all six axes on the seat pan. It also applies to the three translational axes at the seat-back and the feet of seated persons. The ISO 2631-1 Standard also defines weighting filters to modify the frequency response of the data, giving greater prominence to those frequencies where humans are most sensitive to vibration. The frequency weightings $W_{k}(f)$ for vertical axis and seat surface was used for simulations.

In Table A2, scaling of frequency weighted vertical acceleration vibration acting on seated human body according to the ISO 2631-1 is presented as companion data reflecting the response of a vehicle to the uneven road surface. 
Table A2

Expected comfort reactions to vibration environments according to the ISO 2631-1 [11]

\begin{tabular}{cl}
\hline $\begin{array}{c}\text { Range of r.m.s. values of frequency weighted } \\
\text { vertical acceleration on seat }\left[\mathrm{m} / \mathrm{s}^{2}\right]\end{array}$ & Comfort level \\
\hline$<0.315$ & not uncomfortable \\
$0.315-0.63$ & A little uncomfortable \\
$0.5-1$ & fairly uncomfortable \\
$0.8-1.6$ & uncomfortable \\
$1.25-2.5$ & very uncomfortable \\
$>2$ & extremely uncomfortable \\
\hline
\end{tabular}

\section{Short characterization of standard EN 13036-5: 2006 [9]}

The purpose of EN 13036-5 Standard [9] is to standardise various possible characterisations of the road profile unevenness such as the International Roughness Index computation procedure, wave bands analyses as well as Power Spectral Density analyses. The objective is not to impose a single specific procedure but to insure that when applying one of the possible procedures exactly the same steps are carried out with the aim at facilitating the comparison of unevenness measurements carried out with different profiling instruments in European countries.

It is beyond the scope of EN 13036-5 Standard to provide reference values for these indices, or to provide detailed information about the characteristics of profilometers.

EN 13036-5 Standard defines different possible methods for processing digitised road profiles:

- Computation of the IRI, based on the Golden car characteristics.

- Wave band analysis, considering basic statistics (variance, mean-square value) in three partial wave-length bands of the wavelength spectrum (long, medium, short).

- Spectrum analysis, based on the PSD (this part has been partially taken-over from the ISO 8608).

\section{Short characterization of the International Roughness Index (IRI) [2,23]}

$I R I$ is an index defined as a result of applying the algorithm proposed by Sayers $[2,23]$ on the measured realization of the longitudinal profile.

In principle, this algorithm works as follows:

- Elevations along the measured road section are measured at equally spaced distance points.

- The local slopes are evaluated from the elevation data for each distance point.

- The local slopes are used as input into a two-mass model simulating the standard reference vehicle (the so-called Reference-Quarter-Car-Simulation, RQCS) the response of which at the $80 \mathrm{~km} / \mathrm{h}$ travel speed is calculated for each distance point.

- From the filtered data, the differences of slopes of the sprung and unsprung masses are computed and absolute values of them (the so-called rectified slopes) are evaluated.

- The mean value of all rectified slopes gives the IRI.

\section{Appendix 2}

\section{THE VEHICLE MODELS}

\section{The planar model of personal car}

The linear planar model of the personal car [25] used has 12 DOF (Fig. A1) encompassing an enlarged human body model according to the Standard ISO 5982: 2001 [12]. The natural frequencies of 12 DOF model are as follows: $f_{\varphi 2}=1.12 \mathrm{~Hz}$ (vehicle body pitching), $f_{\mathrm{x} 2}=1.08 \mathrm{~Hz}$ (vehicle body bouncing), $f_{\mathrm{x} 5 \mathrm{~d}}=3.40 \mathrm{~Hz}$ (mass $m_{5 \mathrm{~d}}$ bouncing), $f_{\mathrm{x} 5 \mathrm{p}}=3.55 \mathrm{~Hz}$ (mass $m_{5 \mathrm{p}}$ bouncing), $f_{\mathrm{x} 4 \mathrm{~d}}=f_{\mathrm{x} 4 \mathrm{p}}=5.42 \mathrm{~Hz}$ (masses $m_{4 \mathrm{~d}}$ and $m_{4 \mathrm{p}}$ bouncing), $f_{\mathrm{x} 1 \mathrm{f}}=10.93 \mathrm{~Hz}$ (front axle bouncing), $f_{\mathrm{x} 1 \mathrm{r}}=12.88 \mathrm{~Hz}$ (rear axle bouncing), $f_{\mathrm{x} 6 \mathrm{~d}}=f_{\mathrm{x} 6 \mathrm{p}}=24.29 \mathrm{~Hz}\left(\right.$ masses $m_{6 \mathrm{~d}}$ and $m_{6 \mathrm{p}}$ bouncing), $f_{\mathrm{x} 3 \mathrm{~d}}=f_{\mathrm{x} 3 \mathrm{p}}=35.14 \mathrm{~Hz}$ (masses $m_{3 \mathrm{~d}}$ and $m_{3 \mathrm{p}}$ bouncing). The passenger car model parameters may be found in [25]. Geometrical parameters of the vehicle model are the following: $d_{\mathrm{f}}=1.1 \mathrm{~m}, d_{\mathrm{r}}=1.3 \mathrm{~m}, d_{\mathrm{d}}$ $=0.42 \mathrm{~m}$, and $d_{\mathrm{p}}=1 \mathrm{~m}$. The static wheel force is $6 \mathrm{kN}$ for the front axle and $5.2 \mathrm{kN}$ for the rear axle. 


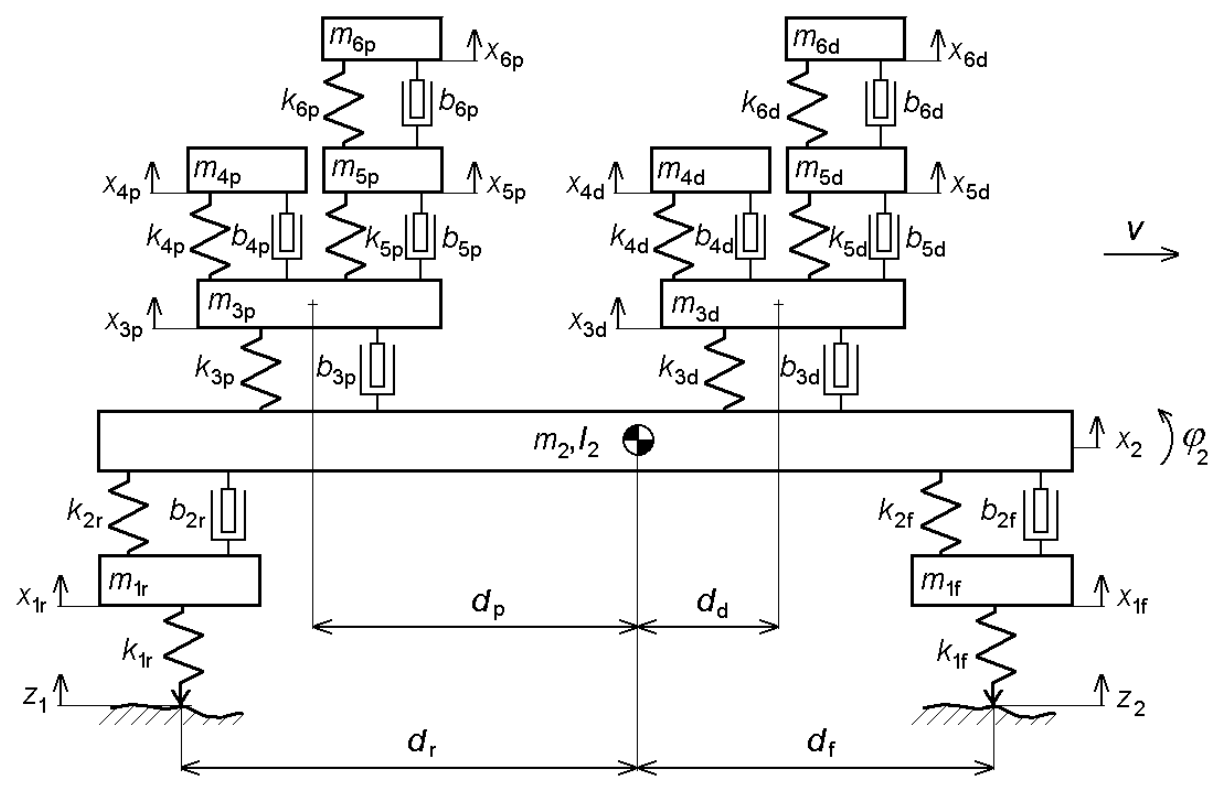

Fig. A1. The planar model of personal car with 12 degrees-of-freedom.

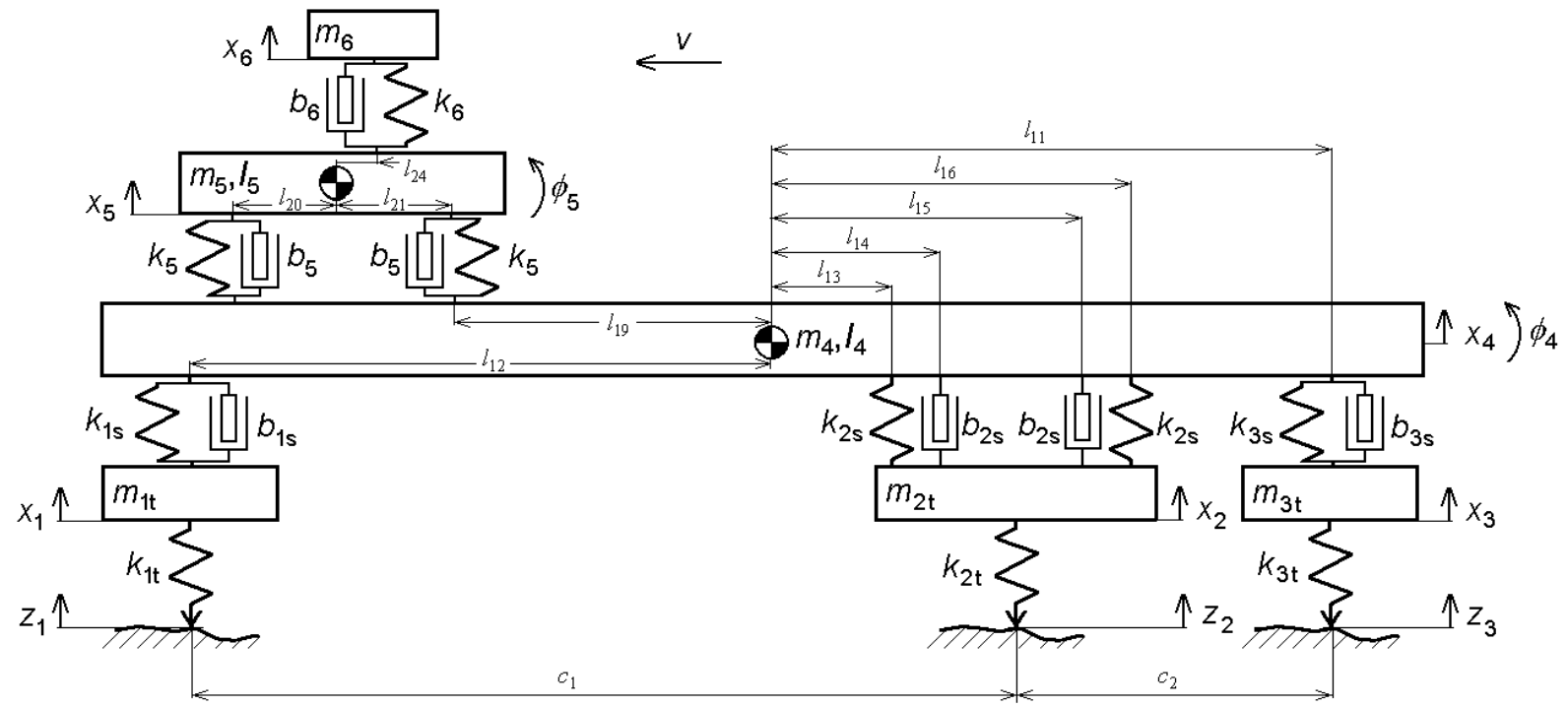

Fig. A2. Three-axle truck planar model with 8 degrees-of-freedom.

The planar model of three-axle truck

The linear planar model of the truck [18] has 8 DOF encompassing three-axles, loading area, suspended cabin and driver's body (Fig. A2). The natural frequencies of truck model used are as follows: front axle, $9.07 \mathrm{~Hz}$; middle axle, $9.79 \mathrm{~Hz}$; rear axle, $8.49 \mathrm{~Hz}$; sprung body mass bouncing, $1.13 \mathrm{~Hz}$; sprung body mass pitching, $6.68 \mathrm{~Hz}$; cabin bouncing, $2.73 \mathrm{~Hz}$; cabin pitching, $3.37 \mathrm{~Hz}$; and driver bouncing, $1.94 \mathrm{~Hz}$. The truck model parameter set assumed may be found in [18]. Geometrical parameters of the truck model are the following: $l_{11}=3.812 \mathrm{~m}, l_{12}=5.042 \mathrm{~m}$, $l_{13}=0.428 \mathrm{~m}, l_{14}=0.628 \mathrm{~m}, l_{15}=1.068 \mathrm{~m}, l_{16}=1.268 \mathrm{~m}, l_{19}=3.212 \mathrm{~m}, l_{20}=0.84 \mathrm{~m}, l_{21}=0.96 \mathrm{~m}, l_{24}=$ $0.26 \mathrm{~m}, c_{1}=5.89 \mathrm{~m}, c_{2}=2.964 \mathrm{~m}$. The static wheel force is $52.7 \mathrm{kN}$ for the front axle, $59.5 \mathrm{kN}$ for the middle axle and $54.9 \mathrm{kN}$ for the rear axle. The dual tyre is mounted on the second (driven) axle. The first and third axles are equipped with single tyres. 


\section{Appendix 3}

Proposal of road classification scheme

Table A3

Proposal of verbally classification of longitudinal road unevenness using $C$ and $w$

\begin{tabular}{lccc}
\hline \multirow{2}{*}{ Verbal quality specification } & \multicolumn{3}{c}{ Road category according to travel speed $[\mathrm{km} / \mathrm{h}]$} \\
\cline { 2 - 4 } & \multicolumn{3}{c}{90} \\
\cline { 2 - 4 } & \multicolumn{3}{c}{$C\left[10^{-6} \mathrm{rad} \mathrm{m}\right]$} \\
\hline excellent & $<2.7$ & 60 \\
very good & $2-4$ & $2.7-5.4$ & $4-8$ \\
good & $4-8$ & $5.4-10.8$ & $8-16$ \\
satisfactory & $8-16$ & $10.8-21.6$ & $16-32$ \\
unqualified & $>16$ & $>21.6$ & $>32$ \\
\hline
\end{tabular}

\section{Correction factor for waviness}

From the measured pair $\{C, w\}$ for a road in question, the correction factor $K_{\mathrm{w}}$ depending on waviness $w$ is taken from Table A4 given below for particular road category.

Table A4

Correction factor $K_{\mathrm{w}}$

\begin{tabular}{lcccccccccccccccccc}
\hline Road category & \multicolumn{10}{c}{$K_{\mathrm{w}}[1]$} \\
\cline { 2 - 15 }$w[1]$ & 1.5 & 1.6 & 1.7 & 1.8 & 1.9 & 2 & 2.1 & 2.2 & 2.3 & 2.4 & 2.5 & 2.6 & 2.7 & 2.8 & 2.9 & 3 \\
\hline $120 \mathrm{~km} / \mathrm{h}$ & 1.319 & 1.226 & 1.15 & 1.088 & 1.038 & 1 & 0.971 & 0.952 & 0.941 & 0.939 & 0.945 & 0.959 & 0.982 & 1.015 & 1.058 & 1.112 \\
$90 \mathrm{~km} / \mathrm{h}$ & 1.413 & 1.296 & 1.2 & 1.12 & 1.054 & 1 & 0.957 & 0.924 & 0.899 & 0.882 & 0.873 & 0.872 & 0.877 & 0.89 & 0.911 & 0.941 \\
$60 \mathrm{~km} / \mathrm{h}$ & 1.445 & 1.322 & 1.219 & 1.133 & 1.06 & 1 & 0.95 & 0.91 & 0.878 & 0.854 & 0.837 & 0.826 & 0.822 & 0.824 & 0.832 & 0.847 \\
\hline
\end{tabular}

Note: The $C_{\mathrm{w}}$ value corrected for $w$ (rounded for the nearest value in the Table A4) is computed as $C_{\mathrm{w}}=K_{\mathrm{w}} \cdot C$ and this value is used to determine the verbal specification of the road from the basic classification frame, Table A3.

\section{References}

[1] P. Andrén, Power spectral density approximations of longitudinal road profiles, International Journal of Vehicle Design 40 (2006), 2-14.

[2] ASTM E 1926-98, Standard practice for computing International Roughness Index of roads from longitudinal profile measurements, American Society for Testing and Materials, West Conshohocken, PA, 2003.

[3] J.S. Bendat and A.G. Piersol, Random Data: Analysis and Measurement Procedures, Wiley - Interscience, New York, 2000.

[4] H. Braun, W. Liesner, U. Gerz, L. Ohnemüller, D. Altendorfer, P. Sulten, T. Hellenbroich and A. Ueckermann, Sammlung und Auswertung von Strassenunebenheiten. Untersuchungen und Vergleich verschiedener Meßgeẍte und Auswerteverfahren auf Eignung zur routinenmässigen Erfassung und Bewertung des Ebenheitszustandes, Forschung Strassenbau und Strassenverkehrstechnik, Heft Nr. 598, Bundesministerium für Verkehr, Bonn-Bad Godesberg, Germany, 1991.

[5] D.J. Cole and D. Cebon, Truck suspension design to minimize road damage, Proceedings of IMechE, Part D, Journal of Automobile Engineering 210 (1996), 95-107.

[6] Data Pave Online, Release 20, Federal Highway Administration, Available from http://www.datapave.com, 2005.

[7] G. Descornet, Inventory of high-speed longitudinal and transverse road evenness measuring equipment in Europe, FEHRL Technical Note No. 1999/1, Belgian Road Research Centre, Brussels, 1999.

[8] J.B. Ferris (ed.), Road profiles: Measurement, analysis and applications, International Journal of Vehicle Design 36 (2004), $101-301$.

[9] EN 13036-5, Surface characteristics of road and airfield pavements - Test methods - Part 5: Determination of longitudinal unevenness indices, European Committee for Standardization, Brussels, 2006.

[10] ISO 8608, Mechanical vibration - Road surface profiles - Reporting of measured data, International Standardization Organization, Geneva, 1995.

[11] ISO 2631-1, Mechanical vibration and shock - Evaluation of human response to whole-body vibration. Part I: General requirements, International Standardization Organization, Geneva, 1997.

[12] ISO 5982, Mechanical vibration and shock - range of idealized values to characterize seated-body biodynamic response under vertical vibration, International Organization for Standardization, Geneva, 2001.

[13] O. Kropáč and P. Múčka, Relations between characteristics of longitudinal unevenness of roads: a review, Strojnícky časopis $\mathbf{5 4}$ (2003), 49-64, 188-194. 
[14] O. Kropáč and P. Múčka, Indicators of longitudinal road unevenness and their mutual relationships, Road Materials and Pavement Design 8 (2007), 523-549.

[15] O. Kropáč and P. Múčka, Indicators of longitudinal unevenness of roads in the USA, International Journal of Vehicle Design, (2008), (in press).

[16] O. Kropáč and P. Múčka, Effects of longitudinal road waviness on the vehicle vibration response, Vehicle System Dynamics, (2008), (in press).

[17] M. Mitschke and H. Wallentowitz, Dynamik der Kraftfahrzeuge. Band B: Schwingungen, 4th ed., Springer-Verlag, Berlin, 2004.

[18] P. Múčka, The active suspension of heavy vehicle driven axle (in Slovak), Strojnícky časopis 53 (2002), 153-165.

[19] P. Múčka, The influence of the road profile wavelengths on vehicle vibration (in Slovak), Strojnícky časopis 53 (2002), 357-378

[20] N.C. Nigam and S. Narayanan, Applications of Random Vibration, Springer Verlag, Berlin, 1994.

[21] M.W. Sayers, T.D. Gillespie and C.A.V. Queiroz, The international road roughness experiment. Establishing correlation and calibration standard for measurements, Techn. Paper Nr. 45, World Bank, Washington, D.C., 1986.

[22] M.W. Sayers and S.M. Karamihas, The Little Book of Profiling, University of Michigan, MI, 1998.

[23] M.W. Sayers, On the calculation of IRI from longitudinal road profile, Paper No. 950842, Transport Research Board, Washington, D.C., 1995, $24 \mathrm{pp}$.

[24] F. Shube, Beitrag zurnumerischen Simulation des Wirbelsäulenverhaltens eines Kraftfahrers infolge durch Straßenunebenheiten induzierter Ganzkörperschwingungen (in German), PhD thesis, Technical university, Aachen, Germany, 2002.

[25] G.J. Stein and P. Múčka, Theoretical investigation of a linear planar model of a personal car with seated people, Proc. of IMechE, Part D, Journal of Automobile Engineering 217 (2003), 257-268.

[26] B. Steinauer and A. Ueckermann, Die Längsunebeheit - auch die Beanspruchung für die Strasse und Fahrer (in German), Strasse und Autobahn 52 (2001), 445-454.

[27] B. Steinauer, A. Ueckermann and E. Kempkens, Zustandserfassung und -bewertung der Bundesfernstraßen - Verbessertes Verfahren zur Beurteilung der Längsebenheit (in German), Strasse and Autobahn 54 (2003), 29-37.

[28] L. Sun, Developing spectrum-based models for International Roughness Index and Present Serviceability Index, Journal of Transportation Engineering 127 (2001), 463-470.

[29] M. Willet, G. Magnusson and B.W. Ferne, FILTER experiment - Theoretical study of indices, FEHRL Tech. Note 2000/02, Transport Research Laboratory, Crowthorne, Berkshire, UK, 2000. 

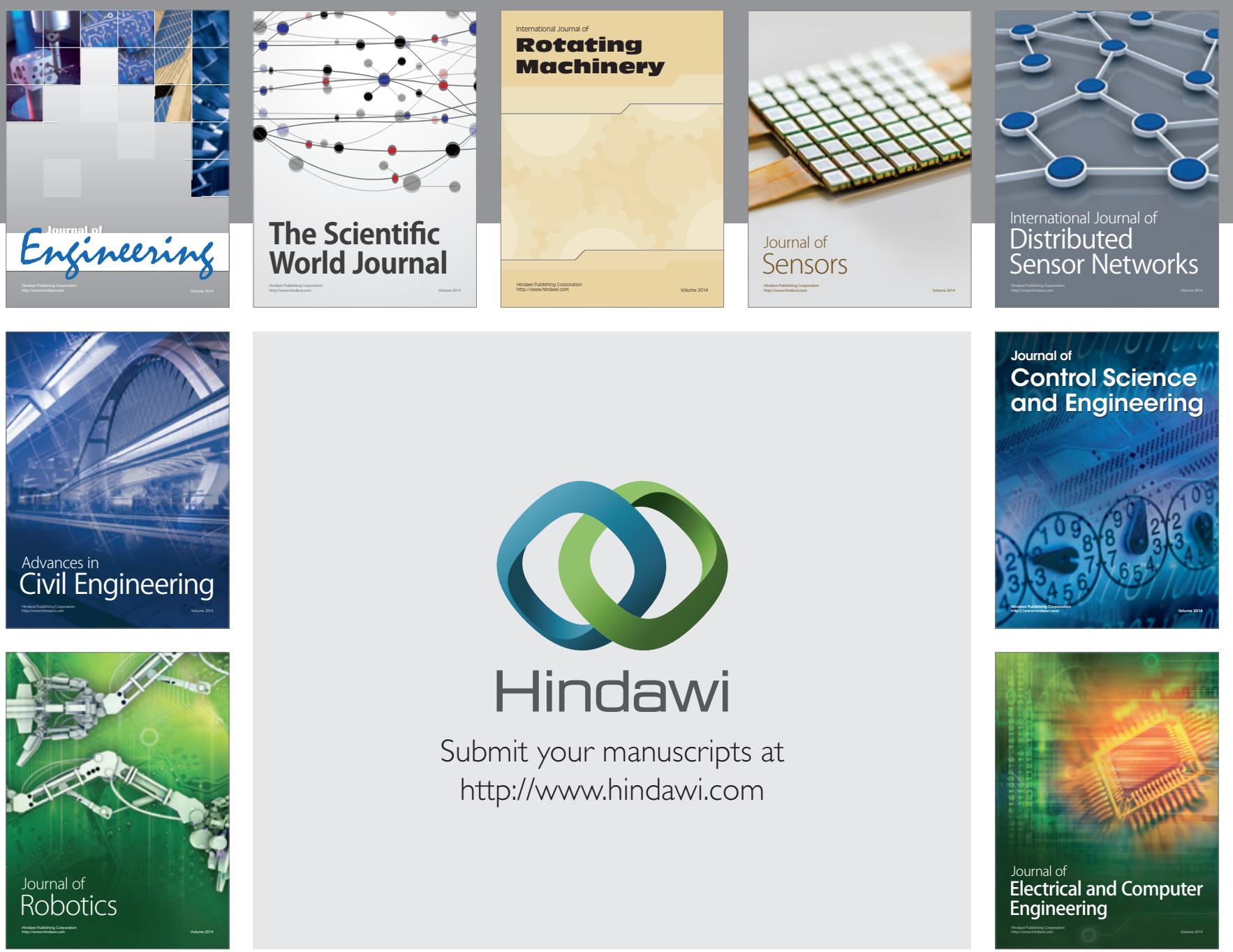

Submit your manuscripts at

http://www.hindawi.com
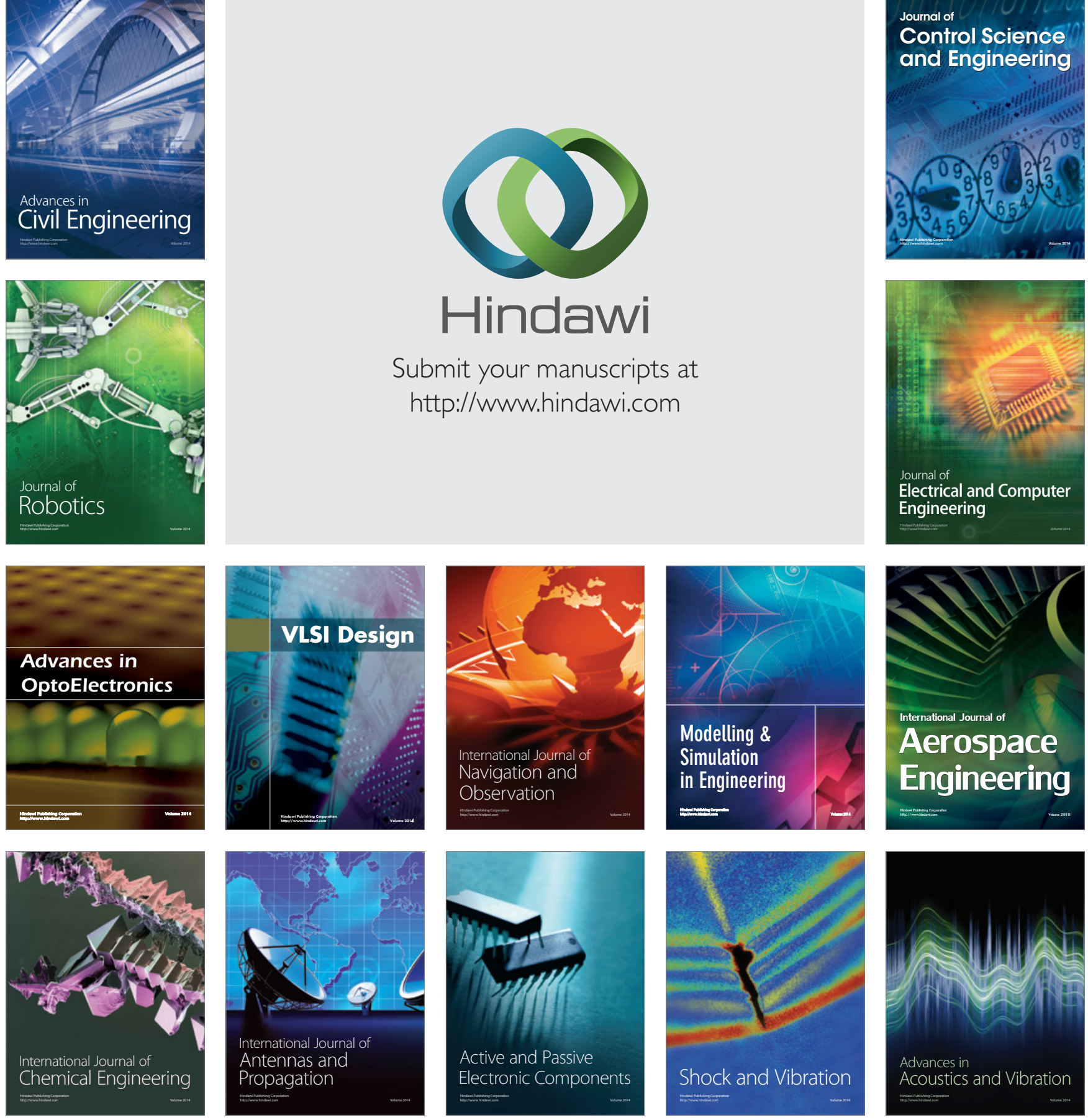